\title{
Accurate reaction time research with the TRS-80 microcomputer
}

\author{
G. ROBERT GRICE \\ University of New Mexico, Albuquerque, New Mexico 87131
}

\begin{abstract}
Procedures for reaction time research with 1-msec accuracy are described using the video display of the TRS-80 microcomputer. The LVB Corporation interface is also employed. Use of the cassette recorder as a voice key in this research is illustrated. A sample assembly language program is presented.
\end{abstract}

Accurate and efficient reaction time (RT) research may be conducted with the TRS -80 microcomputer. Some of the major details of one way in which this may be done are described here. The present discussion is in terms of the Model I TRS-80 in use in our laboratory. While a substantial number of these are now in use for psychological research, it has recently been replaced by Model III, a very similar system also based on the Z-80 microprocessor and largely software compatible. An LVB Corporation interface makes much of the efficiency possible. Our interface consists of a buffered extension of the TRS- 80 buss, eight voltage outputs, a timer which counts in milliseconds, and eight switch inputs. These three cards are addressed through the TRS- 80 I/O ports. In the present application the inputs are in Port 1 , the timer is in Ports 10 and 11 , and the outputs are in Port 128.

For $1-\mathrm{msec}$ accuracy the BASIC interpreter is too slow and, consequently, stimulus presentation, timing, and response detection must be controlled by a machine language subroutine. If simple auditory or light stimuli are used, they may be controlled by the voltage outputs. However, we are using alphanumeric stimuli presented on a separate TV monitor located in a sound chamber. This is a considerable convenience in the conduct of an experiment. For example, portions of the subject's screen may be masked so that instructions and additional information are available only to the experimenter, who may conduct the experiment from a remote location. In Model I, only a $Y$ connection of each of the three lines in the video output cable is required for two monitors. This may be done readily with one male and two female DIN connectors like those used with Model I. The extra monitor should have a 75-ohm input.

The video screen is scanned at a rate of only $60 \mathrm{~Hz}$. However, as pointed out by Reed (1979), 1-msec accuracy may be obtained by synchronizing stimulus

This work was supported by PHS Grant 16400 from the National Institute of Mental Health. Requests for reprints should be sent to G. Robert Grice, Department of Psychology, University of New Mexico, Albuquerque, New Mexico 87131. presentation with the vertical sync signal. Reed described a way of doing this with Apple II. Following this approach with TRS-80, the vertical sync pulse may be introduced into one of the switch inputs of the interface. The opto-isolator on this input must be bypassed. The easiest way to do this is to remove the isolator (4N25) and to insert a jumper in the socket from Pin 2 to $P$ in 5. The pull-up resistor on the isolator output at Pin 5 should be cut. A negative-going pulse to this input sets the bit normally set by a switch closure. The vertical sync pulse, in negative form, is available at Pins 6 and 9 of Z57 on the main PC board of the Model I. ${ }^{1}$ The positive pulse is at Pin 8 . Since this bit will now normally be set, the procedure is first to reset the bit by a read of the port and then to scan for its next occurrence. The reset requires 10 microsec following the IN instruction, so a delay should be introduced before the scan begins. $^{2}$

Perera (1980) has pointed out that the TRS-80 cassette recorder may be used as a voice key and has presented the BASIC instructions necessary. Here, this application in RT research with machine language will be illustrated and some additional information provided. The cassette recorder is addressed through I/O Port 255. When the recorder is placed in the record mode with no tape, and the AUX plug from the computer is removed, the microphone is activated and a sound sets Bit 7 (Decimal 128) in Port 255. The bit is reset by an output to Bit 2 (Decimal 4). However, this bit also starts the recorder motor, which is undersirable for repetitive operation because of wear on the relay contacts that control the motor. This may be prevented by removing the plug from the computer to the remote control jack and inserting a blank, unconnected subminiature phone plug. The relay will still operate but will be switching no load.

A complication arises if one is using wide characters on the screen ( 32 characters per line), since this is also controlled by Port 255. An output of only Bit 2 to this port will return the display to the narrow width, and it is necessary also to set Bit 3. The output for both bits is Decimal 12, which should be used instead of 4 if wide characters are used. If two cassettes are being used with 
the TRS-80 expansion interface, the cassette must also be selected by Memory Location 14,308. Storing zero in this address selects Cassette 1 , and one selects Cassette 2 . It should be mentioned that it will often be more convenient to use a separate, remote microphone rather than the cassette itself. An expensive microphone is not required.

In Figure 1 is an illustrative assembly language source file for a machine language subroutine for a typical RT experiment. We are currently using an auditory warning signal controlled by the voltage output card. A fixation point, a "t" sign, is presented immediately below the place the signal will appear. The present routine assumes that the BASIC program has set the character width to wide and placed the fixation point on the screen. Also, the warning signal has been turned on and the timer started immediately before calling the subroutine.

This program first times the warning signal for $500 \mathrm{msec}$ and then turns it off. Users of the LVB timer will note that the countdown function has not been used for this purpose. We have found that, with highspeed machine language scanning, the countdown bit is missed on about $1 \%$ or $2 \%$ of the trials. Repeatedly

\begin{tabular}{|c|c|c|c|c|}
\hline 00100 & & $\mathrm{ORG}$ & 65401 & ;DEPENDING UPON AVAILABLE RAM \\
\hline 00110 & CAS5EL & EQU & $37 \mathrm{E} Q \mathrm{H}$ & ;CASSETTE SELECT LATCH ADORESS \\
\hline 00120 & SLOC & EQU & 15836 & ; VIDEO ADORESS OF SIGNAL \\
\hline 00130 & FPLOC & EQU & 15900 & ; VIOEO AOORESS OF FIXATION POINT \\
\hline $\begin{array}{l}00140 \\
00150\end{array}$ & & $\begin{array}{l}\text { LD } \\
\text { OUT }\end{array}$ & $\begin{array}{l}A, 128 \\
(10), A\end{array}$ & ;TRANSFER TIME TO BUFFER \\
\hline 00160 & & NOP & & \\
\hline 00170 & & $\begin{array}{l}\text { NOP } \\
\text { NOP }\end{array}$ & & ;WAIT FOR TRANSFER \\
\hline $\begin{array}{l}00180 \\
00190\end{array}$ & & $\begin{array}{l}\text { NOP } \\
\text { IN }\end{array}$ & $A,(1,1)$ & ;GET TIME \\
\hline 00200 & & SUB & & ;TEST FOR 500 MSEC \\
\hline 00210 & & $\mathrm{JP}$ & NZ, TIMEWS & ;CONTINUE UNTIL FOUND \\
\hline 00220 & & LO & A, 64 & \\
\hline 00230 & & OUT & $(10), A$ & ;RESET TIMER \\
\hline 00240 & & LD & A, 0 & \\
\hline 00250 & & OUT & $(128), A$ & ; FURN OFF WARNING SIGNAL \\
\hline 00260 & & OUT & $(10), A$ & ;START TIMER \\
\hline 00270 & & LO & $\mathrm{HL}, W \mathrm{WI}$ & ;GET ADDRESS OF WARNING INTERVAL \\
\hline 00280 & TIMEWI & $\mathrm{LD}$ & $A, 128$ & \\
\hline $\begin{array}{l}00290 \\
00300\end{array}$ & & $\begin{array}{l}\text { OUT } \\
\text { NOP }\end{array}$ & & ;TRANSFER TIME TO BUFFER \\
\hline 00310 & & NOP & & ;WAIT FOR TRANSFER \\
\hline $\begin{array}{l}00320 \\
00330\end{array}$ & & $\underset{\text { NN }}{\text { NOP }}$ & $A,(11)$ & GET TIME \\
\hline 00340 & & SUB & $(\mathrm{HL})$ & ;TEST FOR END OF INTERVAL. \\
\hline 00350 & & $\mathrm{JP}$ & NZ, TIMEWI & ;CONTINUE TESTING UNTIL END \\
\hline 00360 & & LD & $A, 64$ & \\
\hline 00370 & & QUT & (10), A & ;RESEI TIMER \\
\hline 00380 & & IN & $A,(1)$ & ;RESET VERTICAL SYNC BIT \\
\hline 00390 & & NOP & & \\
\hline $\begin{array}{l}00400 \\
00410\end{array}$ & & $\begin{array}{l}\text { NOP } \\
\text { NOP }\end{array}$ & & :10 MICPOSEC REOUIRED FOR RESFT \\
\hline 00420 & & NOP & & ; 10 MICROSEC REQUIRED FOR RESET \\
\hline 00430 & & NOP & & \\
\hline 00440 & VSYNC & IN & $A,(1)$ & :REAO PORT FOR VERT SYNC \\
\hline 00450 & & AND & & ;TEST FOR BIT SEVEN \\
\hline $\begin{array}{l}00460 \\
00470\end{array}$ & & $\mathrm{JP}$ & Z, VSYNC & ;CONT INUE UNTIL BIT SET \\
\hline 00470 & & LD & $A,(S I G)$ & ;GET SIGNAL \\
\hline $\begin{array}{l}00480 \\
00490\end{array}$ & & LD & $(S\llcorner O C), A$ & ;LOAD SIGNAL IN VIDEO RAM \\
\hline $\begin{array}{l}00490 \\
00500\end{array}$ & & LD & $A, 32$ & ;ASCII SPACE \\
\hline $\begin{array}{l}00500 \\
00510\end{array}$ & & $\mathrm{LD}$ & $(F P L O C), A$ & :TURN OFF FIXATION POINT \\
\hline $\begin{array}{l}00510 \\
00520\end{array}$ & & LD & $A, 0$ & \\
\hline 00530 & & $\begin{array}{l}\text { OUT } \\
\text { LD }\end{array}$ & $\begin{array}{l}(10), A \\
(\text { CASSEL) A }\end{array}$ & $\begin{array}{l}\text {;START TIMER } \\
\text {;SELECT CASSETIE I }\end{array}$ \\
\hline 00540 & & LD & $A, 12$ & \\
\hline 00550 & & DUT & $(255), \mathrm{A}$ & ;RESET AUDIO RESPONSE BIT \\
\hline 00560 & TIMERE & IN & $A,\{255\}$ & ;READ CASSETTE INPUT PORT \\
\hline 00570 & & AND & 128 & ;TEST FOR BIT SEVEN \\
\hline 00580 & & JP & $2, T I M E R E$ & ; CONTINUE UNTII. RESPONSE \\
\hline 00590 & & LO & A. 128 & \\
\hline 00595 & & OUT & $(10), A$ & ,TRANSFER TIME TO BUTFER \\
\hline 00600 & & LD & $A, 32$ & ;ASCII SPACE \\
\hline 00610 & & 10 & $(S L O C), A$ & ; TURN OFF SIGNAL \\
\hline 00620 & & RET & & ; RE TURN TO BASIC \\
\hline $\begin{array}{l}00630 \\
00640\end{array}$ & SIG & DEFB & 'A' & ;5PACE FOR SIGNAL \\
\hline 00650 & WI & $\begin{array}{l}\text { DEFB } \\
\text { END }\end{array}$ & 5 & ;SPACE FOR WARNING INTERVAL \\
\hline
\end{tabular}

Figure 1. Assembly language source code for an illustrative machine language subroutine. transferring the count to the timer's buffer and testing with a subtract instruction operates reliably. ${ }^{3}$ The program next times the remainder of the warning interval, which is set here at $500 \mathrm{msec}$. This interval may easily be changed from trial to trial. The BASIC program would POKE the desired interval into the reserved high-memory address (WI) that will be identified by the assembler.

Bit 7 of the switch input card is used for the vertical sync. First the bit is reset and the 10-microsec delay is introduced. The port is then scanned and tested for Bit 7 until the bit is found. The time to find the bit varies from 0 to $16-2 / 3 \mathrm{msec}$. When the bit is set the program then loads the ASCII code for the signal into video RAM, clears the fixation point address, and starts the timer. These operations require only 36 microsec and the vertical scan is still at the top of the screen. After $8 \mathrm{msec}$ the signal is printed on the screen at the address given in the subroutine. Thus, the BASIC program subtracts $8 \mathrm{msec}$ from the recorded RT. After the timer is started, the cassette is selected if necessary, the audio response bit is reset in Port 255, and Port 255 is then scanned and tested for Bit 7 . The scan is at a rate of $63 / \mathrm{msec}$. If switch closures are used instead of the voice key, then Port 1 is scanned and tested by an AND for only those bits used. Experimenters frequently wish to terminate the trial after some arbitrarily long time with no response. In this case, the user alternately tests for the response and the end of the interval. Such a double scan can be conducted with no loss of accuracy. When the response occurs, or an arbitrary time has elapsed (not illustrated here), the timer count is transferred to the buffer within the timer, the signal is turned off, and control is returned to BASIC, where the RT is read from the buffer. If more than one response is used, the response code from the final test is saved in the $\mathrm{HL}$ register pair and returned to BASIC as the value of the variable used in the call instruction. This program requires 99 bytes of protected, high memory when assembled.

The RT signal used here is the letter "A." It may be changed from trial to trial in the same manner as the warning interval. If the signal is more than one character, more space is reserved in high memory, either by multiple use of the pseudo-op, DEFB, or DEFM. If the signal is very long, it is stored in video RAM by a block load instruction (LDIR). In programming for use with wide characters, with 32 characters/line, only the even-numbered video addresses are used.

This sample subroutine will run on Model I. It may require slight modification if used with the Model III assembler. The fundamental logic and content of the program would be the same.

There is another distinct advantage to using an external timer. Since the CPU is not occupied with timing, it is possible to have an accurately timed intertrial interval and still allow the BASIC program to perform the necessary between-trial tasks. All that is necessary is for the program to return to scanning the timer in 
time to catch the end of the interval. A substantial number of chores can be accomplished in an interval of 2 to $4 \mathrm{sec}$. At the end of each trial we print out the $\mathrm{RT}$, error information if applicable, and codes identifying the trial variables. At the end of the session, summary statistics and the RT distributions are printed. The raw data are then saved on tape.

As noted, the interface device is manufactured by LVB Corporation, Lehigh Valley, Pennsylvania. It is also presently distributed by Lafayette Instrument Company, Lafayette, Indiana. The cost is about $\$ 1,000$. The total cost of a complete system, including the interface, computer with 48K RAM, two cassettes, Quick Printer II, and an extra monitor, was about $\$ 3,000$. The cost of Model III is about the same. An external power supply of 5 to $60 \mathrm{~V}$ is required for the voltage outputs and switch inputs. This system provides accuracy and efficiency comparable to a much more expensive one. In addition to the TRS- 80 Models I and III, the interface may be used with Apple II.

For one beginning now with the Model III, I recommend bringing out both the vertical sync pulse and the video signal to jacks installed on the cabinet. Of course, the extra monitor is a luxury not essential to the research. Model III provides for only one cassette: however, two cassettes selected by an external switch would be desirable. In recording data, it is convenient to use a long tape that is not removed between subjects. The cost of a two-disk system is an additional $\$ 1,248$. However, operations go quite smoothly without a disk system.

\section{REFERENCES}

Perera, T. B. Using the TRS-80 cassette tape recorder as a voice key. Behavior Research Methods \& Instrumentation, 1980, 12, 259-260.
ReEd, A. V. Microcomputer display timing: Problems and solutions. Behavion'Research Methods \& Instrumentation, 1979, 11, 572-576.

\section{NOTES}

1. At this writing, it is not possible to give the location of the vertical sync pulse for Model III. While now listed in the catalog, the technical reference manual for Model III has not yet been delivered to stores. It should be noted that opening the cabinet to make this modification will void the 90-day warranty if still in effect. Thus, the unit should be thoroughly tested before it is done. It is also recommended that the single solder connection be made by someone experienced in working with CMOS integrated circuits. The line may be terminated in a subminiature phone jack installed on the back of the cabinet for convenience.

2. Use of the vertical sync pulse permits limited use of the TRS-80 video display as a tachistoscope. For example, stimulusonset asynchrony can be accurately controlled by counting the pulses with machine language. However, time intervals are limited to multiples of $16-2 / 3 \mathrm{msec}$. The time required to print a single line of characters is 442 microsec, which should be fast enough for some research purposes. The time occupied by the blank space between lines is 316 microsec.

3. Very recent information from LVB indicates that this problem with the timer has been corrected in all timer cards shipped after June 1, 1981. Also, the company will make this modification in existing cards without charge. However, the subtraction method used here remains about equally efficient. The scan is a little faster with the countdown procedure since the time need not be transferred. However, the "time-out" bit must be reset and the timer loaded before the scan begins. The subtraction method is preferable for terminating the trial after some finite time with no response.
(Received for publication May 20, 1981; revision accepted September 10,1981.) 